\title{
The Impact of Cultural Intelligence on Employee Job Performance: An Empirical Study on King Abdel-Aziz Hospital in Al-Taif Governorate, Kingdom of Saudi Arabia
}

\author{
Wageeh A. Nafei ${ }^{1}$ \\ ${ }^{1}$ Menoufia University, Shebin El-Kom, Menoufia, Arab Republic of Egypt \\ Correspondence: Wageeh A. Nafei, Menoufia University, Shebin El-Kom, Menoufia, Arab Republic of Egypt, \\ Egypt. Tel: 11-20-1000-192-097. E-mail: dr.wageeh1965@yahoo.com
}

Received: March 19, 2012

Accepted: May 3, 2012

Published: December 4, 2012

doi:10.5539/ijbm.v8n1p26

URL: http://dx.doi.org/10.5539/ijbm.v8n1p26

\begin{abstract}
This research explores the impact of Cultural Intelligence (CQ) on Employee Job Performance (EJP). One of the intercultural effectiveness outcomes of $\mathrm{CQ}$ is task performance. CQ is an important factor in effective performance and interaction among various industries and environments. In other words, CQ is an important attribute for EJP because employees with high levels of CQ achieve high performance levels.

This study was conducted at King Abdel-Aziz Hospital in Al-Taif Governorate (one of the most popular hospitals in the Kingdom of Saudi Arabia). This research is categorized in survey-type studies and is an applied form in terms of its goals. It is descriptive in terms of the method of data collection.

The present study investigates the evaluative attitudes of the employees towards CQ and EJP. This study will also delineate the impact of CQ on EJP. Two groups of employees at the hospital were examined. Out of the 300 questionnaires that were distributed, 280 usable questionnaires were returned, a response rate of $93 \%$. The finding reveals that there are differences among the two groups of employees regarding their evaluative attitudes towards CQ and EJP. Also, this study reveals that the aspects of CQ have a significantly direct effect on EJP. Accordingly, the study produced a set of recommendations including the necessity to pay more attention to the $\mathrm{CQ}$ as one of the key managerial competencies needed for dealing effectively with people from different cultural backgrounds on the one hand, and to raise the level of EJP on the other hand.
\end{abstract}

Keywords: cultural intelligence, employee job performance

\section{Introduction}

In today's global society, Cultural Intelligence (CQ) is a key managerial competency that is mandatory for leading effectively (Arora \& Rohmeta, 2010). Consequently, the $21^{\text {st }}$ century organizational leader must be equipped with the right tools to be effective, emphatic, and efficient in all aspects of the workplace (Kaifi, 2009a). The common denominator in being a successful manager is to embrace the importance of developing high levels of CQ.

The foundation of CQ studies date back to the early 1960s organizational research on culture and intelligence. Years later, researchers merged these concepts, resulting in two existing approaches (Ng \& Earley, 2006). The first approach concentrates on the cultural variation of intelligence. The second approach focuses on the concept of CQ (Earley, 2002). Cultural variation theory emphasizes that the concept of intelligence is culture-bound; its meaning, development, display and assessment are all embedded in the cultural context (Berry \& Ward, 2006) while CQ is claimed to be a culture-free concept that highlights the ability to adapt effectively in different cultural contexts. These two concepts are interrelated, as culturally intelligent individuals need to understand what intelligent behaviors constitute in different cultures ( $\mathrm{Ng} \&$ Earley, 2006). In this study, we concentrate on the second approach, that is the CQ approach, because of its impact on today's global workplace where the ability to adapt to different people from different cultural backgrounds is paramount.

In sum, early research viewed intelligence as the ability to solve problems in academic settings; there is now increasing consensus that intelligence may be displayed in places other than the classroom (Sternberg \& Detterman, 1986).

This research examines the concept of CQ as a predictor of work performance in areas where cross-cultural 
communication takes place. This area of research has not been investigated widely outside the U.S. and South East Asia. There are recommendations for further research on the subject in Europe, Latin America and the Middle East (Ang, et al., 2010).

This research focuses on how CQ affects the Employee Job Performance (EJP) at King Abdel-Aziz hospital in Al-Taif Governorate. There are some studies that have been conducted on the relationship between CQ and EJP (Ang, et al., 2004; 2007). However, the aforementioned studies provided inconclusive evidence and as a result, it is still uncertain whether CQ is the determinant of job performance. Furthermore, no study has been conducted in Kingdom of Saudi Arabia.

This study strives to identify the extent of similarities or differences among the diverse employees of King Abdel-Aziz hospital in Al-Taif Governorate relating to CQ and EJP. Also, it will recognize and describe the type and degree of the relationship between CQ and EJP. This will help researchers analyze the impact of CQ on JEP, particularly in the context of King Abdel-Aziz hospital. It will also depict the importance of CQ in increasing the effectiveness of the organization and investigate the evaluative attitudes of the employees in King Abdel-Aziz hospital towards CQ and EJP. It will illustrate the impact of CQ on EJP. In other words, it will illustrate how CQ influences the EJP.

This article consists of five sections. The first section gives a theoretical construct of CQ and EJP. The second section presents the research design. The third section deals with the study methodology. This includes the population and sample of research, the procedure of data collection, the research variables and method of measuring, and an overview of the statistical tests used in the study. The fourth section presents the empirical results and discussion. The last section embraces the main conclusions and some recommendations for improving CQ and EJP at King Abdel-Aziz hospital in Al-Taif Governorate, KSA.

\section{Literature Review}

In this section, an insight into theoretical construct of CQ, EJP and the impact of CQ on EJP is to be presented.

\subsection{Cultural Intelligence (CQ)}

CQ is consistent with Schmidt \& Hunter's (2000) definition of general intelligence as the ability to grasp and reason correctly with abstractions and solve problems. There are different forms of intelligence. For example, there is social intelligence, emotional intelligence, and practical intelligence. Thus, it is important for a leader to know his or her strengths as a "carpenter knows his tools" (Rath \& Conchie, 2009, p. 13). CQ is a specific form of intelligence focused on capabilities to grasp, reason and behave effectively in situations characterized by cultural diversity (Schmidt \& Hunter, 2000). CQ can be simply defined as an individual's capability and capacity to effectively deal with people from different cultural backgrounds.

There are two types of CQ: an organizational CQ and a geographic/ethnic culture related to CQ. The first describes one's capacity to socialize quickly and effectively in an organization; the second is about being globally literate (Earley \& Mosakowski, 2004). "The workforce of any organization can be quite diverse, with workers coming from any part of the world" (Mujtaba \& Kaifi, 2010). CQ is personal ability and capability for effective performance in situations where it differs culturally. CQ allows managers the ability to deal with multicultural situations in a respectful and effective manner. For example, the verbal delivery of being direct or indirect when delegating tasks can be influenced by a diverse workforce. Some cultures prefer direct orders while others may be offended by them. Being able to appreciate and understand this multidimensional phenomenon is an example of CQ.

The concept of CQ represents an individual's capability to function and manage effectively in culturally diverse settings and is a specific form of intelligence focused on capabilities to grasp, reason, and behave effectively in situations characterized by cultural diversity (Earley \& Ang, 2003; Earley \& Mosakowski, 2004).

$\mathrm{CQ}$ is a multidimensional construct targeted at situations involving cross-cultural interactions arising from differences in race, ethnicity, and nationality (Ang et al., 2007). CQ is distinct from cultural adaptation (NG \& Earley, 2006). It should be noted that past research does not focus on general individual capability and effectiveness in situations with cultural diversity (Ang et al., 2008).

Developing CQ takes both time and dedication because one must be able to identify behaviors that are universal, behaviors that are cultural or religious-based, and differentiate other behaviors that are personal to a particular event. Thus, CQ is a skill that is continuously improved over one's lifetime. As a matter of fact, Geert Hofstede conducted a significant study in the late 1960s and early 1970s relating to cultural values. Based on his research, Hofstede (2001) was able to come up with several distinct dimensions: individualism-collectivism, power distance, uncertainty avoidance, and masculinity-femininity. These dimensions have formed the foundation of 
understanding how different cultures function. The following table provides a quick overview of Hofstede's dimensions of cultural values.

Table 1. Overview of Hofstede's dimensions of cultural values

\begin{tabular}{|c|c|}
\hline \multicolumn{2}{|c|}{ Individualism-Collectivism } \\
\hline Individualistic & Collectivistic \\
\hline People take care of themselves. & People take care of others. \\
\hline \multicolumn{2}{|c|}{ Power Distance } \\
\hline Low & High \\
\hline Power is distributed uniformly. & Power is distributed unequally. \\
\hline \multicolumn{2}{|c|}{ Uncertainty Avoidance } \\
\hline Low & High \\
\hline \multirow{2}{*}{\multicolumn{2}{|c|}{ Masculinity-Femininity }} \\
\hline & \\
\hline $\begin{array}{c}\text { Masculine } \\
\text { Value male traits. }\end{array}$ & $\begin{array}{c}\text { Feminine } \\
\text { Value female traits. }\end{array}$ \\
\hline
\end{tabular}

As the research on cultural intelligence evolves, it becomes imperative to note that there may be a positive correlation between cultural intelligence and job performance levels.

\subsection{The Four Factor Model of CQ}

CQ is a multidimensional construct consisting of different components. They are qualitatively different but interrelated capabilities (Ang et al., 2010). The four components are meta-cognitive CQ, cognitive CQ, motivational CQ, and behavioral CQ (Earley \& Ang, 2003). These four aspects of CQ are necessary for effective and efficient management in diverse cultural environments. Overall, meta-cognitive, cognitive, motivational and behavioral are different capabilities which shape full CQ concept all together. Each aspect of $\mathrm{CQ}$ is explained as follows:

1) Motivational CQ emphasizes desire and self-efficacy. The motivational element of CQ provides an employee the capacity to complete tasks with passion and dedication.

2) Cognitive $C Q$ refers to understanding the norms, practices, and traditions in different cultural settings acquired from education and personal experience.

3) Meta-cognitive $C Q$ is concerned with the cognitive strategies that are necessary for coping with individuals who may not have the same cultural norms. It is the ability to adjust mental models during intercultural exchanges to allow for a more positive experience for all constituents.

4) Behavioral CQ describes the range of culturally appropriate behaviors relating to verbal and non-verbal actions. For example, a person's tone or facial expression relates to this aspect of cultural intelligence. Furthermore, being sensitive and understanding are other components of this dimension.

Although the four factors of cultural intelligence do not always develop in one particular order, Van Dyne \& Ang (2008) suggest that it can be helpful to think about the four factors of CQ as four steps toward enhanced overall cultural intelligence.

1) Motivational CQ (Drive) provides energy and self-confidence.

2) Cognitive $\mathbf{C Q}$ (Knowledge) provides an understanding of basic cultural norms.

3) Meta-cognitive CQ (Strategy) provides direction for planning and interpreting what is going on in diverse contexts.

4) Behavioral CQ (Action) provides an understanding to engage in effective situational leadership across cultures.

The four dimensions of CQ allow a manager to effectively lead in culturally diverse settings.

\subsection{The Measurement of CQ}

There are several attempts at developing models and introducing scales to determine and measure CQ. The Social Cultural Adjustment Model was developed by Black et al in 1991. It identifies three dimensions to be 
used when evaluating how well international managers adjust to working in other cultures, social cultural adjustment, work adjustment and general adjustment to the environment (Gabel et al., 2005).

There is a further attempt to measure $\mathrm{CQ}$, which consists of three components; cognitive, physical and emotional. CQ resides in the body and the heart as well as in the head (Earley \& Mosakowski, 2004).

Alon \& Higgins (2005) referred to another instrument, which they believed showed more promise; "the Cross-cultural Adapability Inventory Test", developed by Kelley \& Meyers (2004). It is a 50-question test which is divided into four areas reflecting different factors: emotional resiliency, perceptual acuty, flexibility, and personal autonomy.

There is another concept developed and validated by Ascalon et al. (2008), "Cross-Cultural Social Intelligence", which they suggested for assessing employees working in cross-cultural settings. However, as the researchers state, this construct represents a marriage of two relatively disparate literatures, those on social intelligence and cross-cultural communication. To reflect that, the assessment focuses mainly on two criteria, ethnocentrism (cultural aspect) and empathy (social intelligence aspect). The assessment does not address CQ solely; in addition, though supported by content and construct validity, it has not been validated in a criterion-related way (Ascalon et al., 2008).

The measurement for CQ which attracted most attention and recognition by scholars was the (Cultural Quotient) CQ. CQ describes an individual's capability to function and manage effectively in culturally diverse settings (Ang, et al., 2007).

The CQ Scale (CQS) was developed by Earley and Ang to measure the CQ of individuals. It assesses four items for meta-cognitive CQ, six for cognitive CQ, five for motivational CQ and five for behavioral CQ. It is a self rating scale consisting of 20 items; taking this test means giving oneself a mark from 1 (disagree) to 5 (strongly agree) on each of the items (Van Dyne et al., 2008, 2010; Moon, 2010). Those with high levels of CQ are much more successful when interacting with people from different cultures. Conversely, those with low levels of CQ are less successful when interacting with people from different cultures.

\subsection{Employee Job Performance (EJP)}

The study of an employee's job performance has become increasingly important over the years due to globalization and high levels of competition in the workforce. Managers depend on performance evaluations for learning more about an employee's performance. Furthermore, an employer can use the performance evaluation to either renew or terminate an existing employee contract. As a result, many organizations strive to hire the most talented employees which equates to hiring employees from all over the world. Thus, the purpose of this research is to examine the relationship between CQ and EJP.

\subsection{The Relationship between CQ and EJP}

The majority of the research suggests a relationship between CQ and JEP (Adidam et al., 2009; Deng \& Gibson, 2009). More specifically, below are some of the connections:

1) Cognitive CQ: Those with CQ will have a more a better understanding or role expectations.

2) Meta-cognitive CQ: Those with high meta-cognitive CQ with know how to effectively apply their cultural knowledge.

3) Motivational CQ: Those with motivational CQ will have higher task performance, will be able to influence others, and will have a higher internal locus of control.

4) Behavioral CQ: Those with high behavioral CQ are able to use their verbal and nonverbal behaviors to meet the expectations of others.

Thus, the literature review provided a foundation for the research questions and hypotheses.

\section{Research Questions and Hypotheses}

This research aims at answering the following questions:

Question $_{1}$ : Are there essential variations among the employees at King Abdel-Aziz hospital towards CQ?

Question $_{2}$ : Are there primary differences among the employees at King Abdel-Aziz hospital regarding EJP?

Question $_{3}$ : What is the impact of CQ (motivational CQ, cognitive CQ, meta-cognitive CQ, and behavioral CQ) on EJP at King Abdel-Aziz hospital?

This study attempts to test the following hypotheses: 
Hypothesis: ${ }_{1}$ : There is no statistical discrimination among the employees at King Abdel-Aziz hospital towards CQ.

Hypothesis: ${ }_{2}$ There is no statistical discrimination among the employees at King Abdel-Aziz hospital towards EJP.

Hypothesis $_{3}$ : There is no statistically significant impact of CQ (motivational, cognitive, meta-cognitive, and behavioral) on the EJP at King Abdel-Aziz hospital.

\section{Research Method}

The research design of this study is survey. According to Creswell (2008), studies carried out by using the survey method is able to collect data directly from the subject under review and to make generalizations onto the population. For quantitative data, a set of questionnaire will be administered to the respondents.

The research method section includes the research population and sample, method of data collection, research variables, method of measuring, data analysis and testing hypotheses.

\subsection{Population and Sample of Research}

The present paper is interested in evaluating the impact of CQ on EJP at King Abdel-Aziz Hospital in Al-Taif Governorate, Kingdom of Saudi Arabia. This is why the population involves all categories of employees (physicians, nurses, administrative staff and auditors). This hospital has been chosen for applying the field study as it is the biggest governmental hospital in Al-Taif Governorate. It cost 700 million riyals for construction, while its capacity amounts to 600 beds. It involves all medical and remedial specializations, along with developed medical cadres who work at this gigantic hospital. The most important specializations include intensive care, surgery, internal medicine, newborns, radiology, pharmacy, laboratory, incubators, etc. The medical and health services provided by this hospital are equal to those of the developed major hospitals in Kingdom of Saudi Arabia (Planning Administration, King Abdel-Aziz Hospital in Al-Taif, 2012).

Total items of the research population amount to 1387. The researcher has drawn on the samples method for collecting the primary data needed for the study as it was difficult to have access to all items of the research population, besides time limitations. The researcher has drawn on the stratified random sample while selecting items from the different categories of employees. Sampling size has been decided according to the following equation (Edris, 2004).

$$
n=\frac{N \times(\mathrm{Z})^{2} \times P(1-P)}{N e^{2}+(\mathrm{Z})^{2} \times P(1-P)}
$$

(n) refers to sampling size, $(\mathrm{N})$ refers to size of the population of the study, $(\mathrm{Z})$ refers to permissible error limits, 1.96 at $95 \%$ of confidence, (P) refers to number of items at the feature under study, $50 \%$, (e) refers to permissible sample error while evaluating proportion, $50 \%$. Using the above-mentioned equation, size of the sample is $=300$ items. The relative distribution of the sample has been done in light of the proportion of the number of employees in the research population. Distribution of the sample size is presented in Table 2.

Table 2. Distribution of the sample size on the population

\begin{tabular}{cccc}
\hline Job Category & Number & Percentage & Size of Sample \\
\hline Physicians & 279 & $20 \%$ & $300 \times 20 \%=60$ \\
Nurses & 582 & $42 \%$ & $300 \times 42 \%=126$ \\
Administrative staff & 246 & $18 \%$ & $300 \times 18 \%=54$ \\
Auditors & 280 & $20 \%$ & $300 \times 20 \%=60$ \\
Total & $\mathbf{1 3 8 7}$ & $\mathbf{1 0 0} \%$ & $300 \times 100 \%=300$ \\
\hline
\end{tabular}

Source: Personnel Department at King Abdel-Aziz Hospital, Al-Taif Governorate, KSA, 2011

Finally, items of each sample of the above-mentioned categories have been chosen randomly using the lists of employees at the staff Affairs Department, King Abdel-Aziz Hospital in Al-Taif Governorate, KSA. 
Concerning the features of the sample units, Saudi staff amounted to about $31.4 \%$ while non-Saudi staff amounted to $68.6 \%$. Regarding sex, males amounted to about $41.1 \%$ while females amounted to $58.9 \%$. In regard to marital status, the percentage of the married staff in the sample amounted to $54.6 \%$ and single staff $45.4 \%$. As for age, number of participants less than 30 was $37.1 \%$, from 30 to 45 was $52.5 \%$ and more than 45 was about $10.4 \%$. Concerning the educational level, holders of the secondary school certificate amounted to $15.7 \%$, university education $70 \%$ and Master or $\mathrm{PhD}$ degree $14.3 \%$. Regarding the period of experience, the percentage of sample units whose experience was fewer than five years was about $43.9 \%$, from 5 to 10 years was $37.9 \%$ and more than 10 years of experience was $18.2 \%$. Concerning monthly salary, the percentage of sample units whose salary level was less than 5000 riyals was about $60.4 \%$, from 5000 to 15000 riyals was $34.6 \%$ and more than 15000 riyals was $5 \%$.

\subsection{Methods of Data Collection}

The present study has adopted the questionnaire method for collecting primary data as required for the study. The questionnaire list is interested in recognizing CQ and EJP.

The questionnaire used in the questions list included five pages, excluding the introductory page addressing informants. It aims at introducing them about the nature and aims of the study, besides gaining their cooperation for fulfilling the questions in the list. The other pages include a list of direct inquiries posed to all categories of employees at King Abdel-Aziz hospital in Al-Taif Governorate in the same wording and order. This reduces the probability of bias in data collection necessary for the problem of the study.

It is noteworthy that the items of the questionnaire has been piloted by a limited group of employees at King Abdel-Aziz hospital (25 items only). This necessitated some amendments in the questionnaire; some phrases were reworded while others were omitted so as to suit the nature and aims of the present study.

The data of the questionnaire list of the various categories of employees at King Abdel-Aziz hospital in Al-Taif Governorate have been collected by contacting informants in informal interviews to explain the nature and aims of the questionnaire and to seek their cooperation.

The researcher also handed each informant a list of questions and gave them enough time to answer the questions at a suitable time and place for them. All completed lists were retrieved through personal contact. This method is the commonest in collecting primary data and it attains a high percentage of replies.

The questionnaire included three types of questions, in view of problem of the study, its inquiries and purposes of analysis. The first question is related to recognizing CQ, the second question detects EJP, the third question is related to the demographic variables of employees in King Abdel-Aziz hospital in Al-Taif Governorate.

The data collection process took two months. Reply rates were $93 \%$ ( 280 lists out of the 300 distributed). This is due to the high level of interest of the staff of King Abdel-Aziz Hospital in Al-Taif Governorate in the subject matter of the questionnaire, on the one hand, and the ease and clarity of questions, on the other hand.

\subsection{Research Variables and Methods of Measuring}

\subsubsection{Cultural Intelligence CQ}

The present study considers CQ as an independent variable. Aspects of CQ include meta-cognitive CQ, cognitive CQ, motivational CQ, and behavioral CQ. The researcher has employed the measure developed by (Van Dyne et al., 2010; Moon, 2010) to measure CQ. It is worthy of mention that this measure consists of the 20 items. The Cultural Quotient Scale CQS includes four statements for meta-cognitive CQ, six statements for cognitive CQ, five statements for motivational CQ, and five statements for behavioral CQ. Likert measure has been used for agreement or disagreement. It is composed of five degrees, (5) refers to full agreement, while (1) refers to full disagreement and neutral degrees are found in between.

\subsubsection{Employee Job Performance EJP}

The present study investigates EJP as a dependant variable. The researcher has drawn on the scale of Williams and Anderson, 1991 for measuring the EJP. It is important to mention that the respondents were asked to use a five point Likert scale ranging from strongly disagree (1) to strongly agree (5).

\subsection{Method of Data Analysis and Testing Hypotheses}

For purposes of the statistical analysis and hypotheses testing, the researcher has employed the following methods: (1) Alpha correlation coefficient which aims at verifying the degree of reliability in the scale of CQ and EJP, (2) The two-group discriminant analysis aims at discriminating between the categories of employees at the hospital in regard to CQ and EJP, (3) Multiple Regression Analysis (MRA) aims at verifying the type and 
strength of the relationship between CQ and EJP, and (4) The statistical testing of hypotheses which includes Wilk's Lambda and chi-square that goes hand in hand with the discriminate analysis method and F-test and T-test which go hand in hand with the MRA. All these tests accompany analysis means which are to be used. They are found in Statistical Package for Social Science (SPSS).

\section{Hypotheses Testing}

The findings of analysis may be discussed and explained under the following main points: (1) evaluating reliability of scales, (2) CQ, (3) EJP, and (4) the relationship between CQ and EJP.

\subsection{Evaluating Reliability Scales}

The reliability of the scales of CQ and EJP at King Abdel-Aziz hospital were evaluated to minimize errors of measuring and maximize constancy of the scales used. Alpha correlation coefficient (ACC) was used as it is the most widely employed method of analyzing reliability to evaluate the degree of internal consistency among the contents of the scale under testing. According to scales testing in social researches, it was decided to exclude variables that had a correlation coefficient of less than 0.30 when the acceptable limits of ACC range from 0.60 to 0.80 in accordance with levels of reliability analysis in social sciences.

ACC was applied on CQ scale in total manner for the entire scale and each variable of the scale separately. Results revealed that ACC for the scale as a whole represented about 0.938 , which is an indication of a high degree of reliability. The extent of internal consistency among contents of CQ may be illustrated using ACC through table 3 . This reveals that the primary result of evaluating reliability reflects the fact that the scale under testing is reliable for measuring CQ at King Abdel-Aziz hospital.

Table 3. Evaluation of the internal consistency among contents of CQ using ACC, the output of reliability analysis

\begin{tabular}{ccc}
\hline $\begin{array}{c}\text { The Dimension of } \\
\text { CQ }\end{array}$ & $\begin{array}{c}\text { Number of } \\
\text { Statement }\end{array}$ & $\begin{array}{c}\text { Alpha Correlation } \\
\text { Coefficient }\end{array}$ \\
\hline Motivational CQ & 5 & 0.769 \\
Cognitive CQ & 6 & 0.889 \\
Meta-cognitive CQ & 4 & 0.838 \\
Behavioral CQ & 5 & 0.782 \\
Total Measurement & $\mathbf{2 0}$ & $\mathbf{0 . 9 3 8}$ \\
\hline
\end{tabular}

Also, ACC was applied on the scale of EJP in a total manner for the entire scale and for each variable of the scale. Results of analyzing reliability revealed that ACC of the scale represented about 0.863 , which is an indication of a high degree of reliability. This illustrates that the primary findings of reliability evaluation reflect the fact that the scale under testing is reliable for measuring EJP at King Abdel-Aziz hospital.

According to the above-mentioned results, two scales had been defined; the first is for CQ (20 variables), ACC for scales as a whole represented about 0.938 , and the second is for EJP (4 variables), ACC for scales as a whole represented 0.863 . These scales are reliable in the course of the later stages of analysis in the study.

\subsection{Cultural Intelligence CQ}

This section handles the results of the statistical analysis for answering the first question of the study on the verification of the extent of differences and discrimination among the employees in regard to their evaluative attitudes towards CQ and testing the first hypothesis of the study which states:

\section{Hypothesis: $_{1}$ : There is no significant discrimination among the employees at King Abdel-Aziz hospital regarding $C Q$.}

The two-group discriminant analysis was applied on a model including two groups of employees, along with their evaluative attitudes towards CQ at King Abdel-Aziz hospital. The discrimination analysis method was applied on two groups enabling us to answer the previous question as follows:

\section{A-Discriminant Functions and Matrix on the Basis of CQ}

The functions and matrix at King Abdel-Aziz hospital are represented in table 4. This table reveals the following findings: 
1) Eigen values represent 0.15 in the discrimination function among employees and their evaluative attitudes towards CQ.

2) There are differences among attitudes of employees towards CQ (the percentage of differentiation which we could interpret in the model was $100 \%$ of discrimination analysis function).

3) There is a significant relationship between employees and their attitudes towards CQ (multiple correlation coefficient represents 0.36 in the discrimination analysis function).

4) Wilks Lambda value represents 0.87 in the discrimination analysis function.

5) Results of discrimination analysis of the two groups revealed that the value of chi-square represents 38.19 in the discrimination analysis function.

6) The percentage of the accurate classification of employees according to their evaluative attitudes towards CQ is $69 \%$, which implies the differences among employees towards CQ there. Also, there are about $21 \%$ of the employees who are similar in regard to their evaluative attitudes towards CQ.

Table 4. Discriminant functions and matrix on the basis of CQ

\begin{tabular}{|c|c|c|c|c|c|c|c|}
\hline \multicolumn{8}{|c|}{ A-Discriminant Functions } \\
\hline Dala & $\begin{array}{l}\text { Eigen } \\
\text { Values }\end{array}$ & $\begin{array}{c}\text { The } \% \text { of } \\
\text { Differences }\end{array}$ & $\mathrm{MCC}$ & $\begin{array}{c}\text { Wilks } \\
\text { Lambada }\end{array}$ & Ch-Square & $\begin{array}{l}\text { Degree of } \\
\text { Sign }\end{array}$ & $\begin{array}{c}\text { Level of } \\
\text { Sign }\end{array}$ \\
\hline 1 & 0.15 & 100.0 & 0.36 & 0.87 & 38.19 & 20 & 0.000 \\
\hline \multicolumn{8}{|c|}{ B- Discriminant Matrix } \\
\hline & Groups & Number & \multicolumn{3}{|c|}{ Predict Member of Groups } & \multicolumn{2}{|r|}{ Total } \\
\hline & Physicians & 165 & 140 & $8 \%)$ & $25(15.2 \%)$ & & 165 \\
\hline & ministrative & 115 & 63 & $\%)$ & $52(45.2 \%)$ & & 115 \\
\hline & Total & 280 & & & & & 280 \\
\hline \multicolumn{5}{|c|}{ The Percentage of the exact division } & \multicolumn{3}{|c|}{$68.6 \%$} \\
\hline
\end{tabular}

\section{B-The Relative Importance of CQ}

Using the discrimination analysis method, we could define the relative importance of CQ and variables which show more discrimination among employees at King Abdel-Aziz hospital. It included two variables relating to CQ as shown in Table 5.

Table 5. Discrimination coefficients among the faculty members on the basis of KM

\begin{tabular}{lccccc}
\hline The Factor Discriminating among Employees & \multicolumn{2}{c}{ Mean } & F-Test & Level of \\
\hline 1. & Group 1 & Group 2 & & Sig \\
$\quad \begin{array}{l}\text { I know the legal and economic systems } \\
\text { of other cultures. }\end{array}$ & 3.88 & 3.37 & $10.60^{* *}$ & 0.96 \\
$\begin{array}{c}\text { I am conscious of the cultural } \\
\text { knowledge I use when interacting with people } \\
\text { with different cultural backgrounds. }\end{array}$ & 3.83 & 3.92 & $8.71^{* *}$ & 0.94 \\
\hline
\end{tabular}

It is noticeable that the employees are interested in knowing the legal and economic system of other cultures. This is the top factor discriminating among employees (discrimination coefficients represent 0.96. The following variable is that they are conscious of the cultural knowledge they use when interacting with people with different cultural backgrounds (discrimination coefficient represents 0.94). (See table 5).

\section{C-Comparative Description of Employees on the Basis of CQ}

Comparing the mean of the attitudes of employees towards CQ and variables that have more ability to discriminate among them, we could comparatively describe these types, as in Table (4). 
As for physicians and nurses, they tend to agree that they know the legal and economic systems of other cultures (with a mean of 3.89), and they are conscious of the cultural knowledge they use when interacting with people with different cultural backgrounds (with a mean of 3.84).

As for administrative staff and auditors, they tend to agree that they know the legal and economic systems of other cultures (with a mean of 3.37), and they are conscious of the cultural knowledge they use when interacting with people with different cultural backgrounds (with a mean of 3.92).

Accordingly, it was decided to reject the null hypothesis and accept the alternative hypothesis as a whole. This is because it has been clear that there is statistically significant discrimination among employees at the hospital on the basis of evaluative attitudes of employees towards CQ. This decision was based on the value of Wilks Lambda in the discrimination analysis, which amounts to 0.87 (see table 3). Besides the value of chi-square calculated (38.19) in the free degree of (20) in the same discrimination analysis function exceeds its table counterpart (37.56) at the level of statistical significance of 0.01 (see table 3). On the other hand, it was decided to reject the same null hypothesis of two variables of CQ (20 variables) taken individually as there is fundamental discrimination among employees on the basis of each variable at a level of statistical significance of 0.01 , according to the test of univariate F (See table 4).

\subsection{Employee Job Performance (EJP)}

This section handles results of the statistical analysis for answering the second question of this study on the verification of the extent of difference and discrimination among the employees in regard to their evaluative attitudes towards EJP and testing the second hypothesis of the study which states:

\section{Hypothesis $_{2}$ : There is no significant discrimination among the employees at King Abdel-Aziz hospital regarding EJP.}

The two-group discriminant analysis was applied on a model including two groups of employees, along with their evaluative attitudes towards EJP at King Abdel-Aziz hospital. This technique enabled us to answer the previous question as follows:

\section{A-Discriminant Functions and Matrix on the Basis of EJP}

The functions and matrix at the hospital are represented in table 6 . This table reveals the following findings:

1) Eigen values represent 0.06 in the discrimination function among employees and their evaluative attitudes towards EJP.

2) There are differences among attitudes of employees towards EJP (the percentage of differentiation which we could interpret in the model was $100 \%$ of discrimination analysis function).

3) There is a significant relationship between employees and their attitudes towards EJP (multiple correlation coefficient represents 0.25 in the discrimination analysis function).

4) Wilks Lambda value represents 0.94 in the discrimination analysis function.

5) Results of discrimination analysis of the two groups revealed that the value of chi-square represents 17.32 in the discrimination analysis function.

6) The percentage of the accurate classification of employees according to their evaluative attitudes towards EJP is $65 \%$, which implies the differences among employees towards EJP. Also, there are about $35 \%$ of the employees who are similar in regard to their evaluative attitudes towards EJP.

Table 6. Discriminant functions and matrix on the basis of EJP

\begin{tabular}{|c|c|c|c|c|c|c|c|}
\hline \multicolumn{8}{|c|}{ A-Discriminant Functions } \\
\hline Dala & $\begin{array}{l}\text { Eigen } \\
\text { Values }\end{array}$ & $\begin{array}{l}\text { The } \% \text { of } \\
\text { Differences }\end{array}$ & $\mathrm{MCC}$ & $\begin{array}{c}\text { Wilks } \\
\text { Lambada }\end{array}$ & Ch-Square & $\begin{array}{c}\text { Degree of } \\
\text { Sign }\end{array}$ & $\begin{array}{c}\text { Level of } \\
\text { Sign }\end{array}$ \\
\hline 1 & 0.06 & 100.0 & 0.25 & 0.94 & 17.32 & 1 & 0.000 \\
\hline \multicolumn{8}{|c|}{ B- Discriminant Matrix } \\
\hline & Groups & Number & \multicolumn{3}{|c|}{ Predict Member of Groups } & \multicolumn{2}{|r|}{ Total } \\
\hline & Physicians & 165 & 141 & $\%$ & $24(14.5 \%)$ & & 165 \\
\hline & ministrative & 115 & \multicolumn{2}{|c|}{$75(65.2 \%)$} & $40(34.8 \%)$ & & 115 \\
\hline & Total & 280 & & & & & 280 \\
\hline \multicolumn{5}{|c|}{ The Percentage of the exact division } & \multicolumn{3}{|c|}{$64.6 \%$} \\
\hline
\end{tabular}




\section{B-The Relative Importance of EJP}

Using the discrimination analysis method we could define the relative importance of EJP and variables which show more discrimination among employees at the hospital. It included one variables relating to EJP as shown in Table 7.

Table 7. Discrimination coefficients among the faculty members on the basis of EJP

\begin{tabular}{|c|c|c|c|c|}
\hline \multirow{2}{*}{ The Factor Discriminating among Employees } & \multicolumn{2}{|c|}{ Mean } & \multirow{2}{*}{ F-Test } & \multirow{2}{*}{$\begin{array}{l}\text { Level of } \\
\text { Sig }\end{array}$} \\
\hline & Group 1 & Group 2 & & \\
\hline $\begin{array}{l}\text { I sometimes neglect aspects of the job I am obliged } \\
\text { to perform. }\end{array}$ & 4.19 & 3.75 & $17.89^{* *}$ & 0.94 \\
\hline
\end{tabular}

It is noticeable that the employees sometimes neglect aspects of the job they are obliged to perform. This is the top factor discriminating among employees (discrimination coefficients represent 0.946. (See table 7).

\section{C-Comparative Description of Employees on the Basis of EJP}

Comparing the mean of the attitudes of employees towards EJP and variables that have more ability to discriminate among them, we could comparatively describe these types, as in table 7.

As for physicians and nurses, they tend to agree that they sometimes neglect aspects of the job they are obliged to perform (with a mean of 4.19).

As for administrative staff and auditors, they tend to agree that they sometimes neglect aspects of the job they are obliged to perform (with a mean of 3.75).

Accordingly, it was decided to reject the null hypothesis and accept the alternative hypothesis as a whole. This is because it has been clear that there is statistically significant discrimination among employees at the hospital on the basis of evaluative attitudes of employees towards EJP. This decision was based on the value of Wilks Lambda in the discrimination analysis, which amounts to 0.94 (see table 7). Besides the value of chi-square calculated (17.32) in the free degree of (1) in the same discrimination analysis function exceeds its table counterpart (6.64) at the level of statistical significance of 0.01 (see table 7). On the other hand, it was decided to reject the same null hypothesis of one variables of EJP (4 variables) taken individually as there is fundamental discrimination among employees on the basis of each variable at a level of statistical significance of 0.01 , according to the test of univariate $\mathrm{F}$ (See table 7).

\subsection{The Relationship between CQ and EJP}

This section attempts an answer to the third question in this study on the type and degree of the relationship between CQ and EJP along with testing the third hypothesis of the study, which states that:

Hypothesis $_{3}$ : There is no statistically significant relationship between CQ (motivational CQ, cognitive CQ, meta-cognitive CQ, and behavioral CQ) and EJP at King Abdel-Aziz hospital, as a whole and for each variable separately.

This hypothesis has been divided into four subsidiary hypotheses as following:

(1) There is no statistically significant relationship between CQ (motivational CQ) and EJP at King Abdel-Aziz hospital.

(2) There is no statistically significant relationship between CQ (cognitive CQ) and EJP at King Abdel-Aziz hospital.

(3) There is no statistically significant relationship between CQ (meta-cognitive CQ) and EJP at King Abdel-Aziz hospital.

(4) There is no statistically significant relationship between CQ (behavioral CQ) and EJP at King Abdel-Aziz hospital.

The MRA was used to identify the type and strength of the relationship between CQ and EJP. Correlation coefficients between them is illustrated in Table 8 . 
Table 8. Correlation coefficients between CQ and EJP

\begin{tabular}{cc}
\hline The Dimension of CQ & EJP \\
\hline Motivational CQ & $0.459^{* *}$ \\
Cognitive CQ & $0.433^{* *}$ \\
Meta-cognitive CQ & $0.406^{* *}$ \\
Behavioral CQ & $0.444^{* *}$ \\
Total Measurement & $\mathbf{0 . 4 9 3}$ \\
\hline
\end{tabular}

This reveals that there is significant correlation between the aspects of CQ (motivational CQ, cognitive CQ, meta-cognitive CQ, and behavioral CQ) and EJP at King Abdel-Aziz hospital as a whole and for each variable separately.

This section will discuss the relationship between all fields of CQ and EJP. The MRA was employed to identify the type and strength of the relationship between the aspects of CQ and EJP separately. Results of applying the MRA is illustrated as follows:

\subsubsection{The Relationship between CQ (Motivational CQ) and EJP}

Results shown in Table 9 reveal the following:

1) There is a statistically significant relationship between motivational CQ and EJP. It represents 47\%, according to the multiple correlation coefficients.

2) Motivational CQ may interpret about $22 \%$ according to coefficient of determination (R-Square) of the total differentiation in the EJP.

3) The results of MRA reveal that the variables of the motivational CQ that better interpret differences in the EJP, for example, include the fact that " I enjoy living in cultures that are unfamiliar to me" (0.21), "I am sure I can deal with the stresses of adjusting to a culture that is new to me" (0.13), "I am confident that I can get accustomed to the shopping conditions in a different culture" (0.13), "I am confident that I can socialize with locals in a culture that is unfamiliar to me" $(0.12)$ and "I enjoy interacting with people from different cultures" (0.05) as shown in Table 9.

Table 9. The relationship between motivational CQ and EJP

\begin{tabular}{|c|c|c|c|c|}
\hline & The Variables of Motivational CQ & Beta & $\mathbf{R}$ & $\mathbf{R}^{2}$ \\
\hline 1. & I enjoy living in cultures that are unfamiliar to me. & $0.210^{* *}$ & 0.381 & 0.145 \\
\hline 2. & $\begin{array}{l}\text { I am sure I can deal with the stresses of adjusting to a } \\
\text { e that is new to me. }\end{array}$ & 0.132 & 0.339 & 0.114 \\
\hline 3. & $\begin{array}{l}\text { I am confident that I can get accustomed to the shopping } \\
\text { ions in a different culture. }\end{array}$ & $0.131^{*}$ & 0.333 & 0.111 \\
\hline 4. & $\begin{array}{l}\text { I am confident that I can socialize with locals in a culture } \\
\text { unfamiliar to me. }\end{array}$ & 0.116 & 0.332 & 0.110 \\
\hline 5. & I enjoy interacting with people from different cultures. & 0.046 & 0.267 & 0.071 \\
\hline - & Multiple Correlation Coefficients & & 0.468 & \\
\hline - & Coefficient of Determination & & 0.219 & \\
\hline - & The Value of Calculated F & & 15.397 & \\
\hline - & Degree of Freedom & & 5,274 & \\
\hline - & The Value of Indexed F & & 3.017 & \\
\hline - & Level of Significant & & 0.000 & \\
\hline
\end{tabular}

There is no impact of motivational CQ as one of the aspects of CQ on EJP. The alternative hypothesis has been accepted because the model of MRA has shown that there was fundamental relationship at a statistical significance level of 0.01 (according to F-test) between motivational CQ as an independent variable and EJP as a dependent variable at a statistical significance level of 0.01. According to T-test (See table 9). 


\subsubsection{The Relationship between CQ (Cognitive CQ) and EJP}

Results shown in Table 10 reveal the following:

1) There is a statistically significant relationship between cognitive CQ and EJP. It represents $47 \%$, according to the multiple correlation coefficients.

2) Cognitive CQ may interpret about $22 \%$ according to coefficient of determination (R-Square) of the total differentiation in the EJP.

3) The results of MRA reveal that the variables of the cognitive CQ that better interpret differences in the EJP, for example, include the facts that " I know the marriage systems of other cultures" (0.21), "I know the rules for expressing nonverbal behaviors in other cultures" (0.19), "I know the arts and crafts of other cultures" (0.17), "I know the rules (e.g., vocabulary, grammar) of other languages" (0.81), "I know the legal and economic systems of other cultures" (0.067) and "I know the cultural values and religious beliefs of other cultures" (0.18) as shown in Table 10.

Table 10. The relationship between cognitive CQ and EJP

\begin{tabular}{|c|c|c|c|c|}
\hline & The Variables of Cognitive CQ & Beta & $\mathbf{R}$ & $\mathbf{R}^{2}$ \\
\hline 1. & I know the marriage systems of other cultures. & $0.211^{* *}$ & 0.384 & 0.147 \\
\hline 2. & $\begin{array}{l}\text { I know the rules for expressing nonverbal behaviors in other } \\
\text { ures. }\end{array}$ & $0.190^{*}$ & 0.404 & 0.163 \\
\hline 3. & I know the arts and crafts of other cultures. & $0.172^{*}$ & 0.416 & 0.173 \\
\hline 4. & $\begin{array}{l}\text { I know the rules (e.g., vocabulary, grammar) of other } \\
\text { zuges. }\end{array}$ & 0.081 & 0.288 & 0.083 \\
\hline 5. & I know the legal and economic systems of other cultures. & 0.067 & 0.301 & 0.090 \\
\hline 6. & $\begin{array}{l}\text { I know the cultural values and religious beliefs of other } \\
\text { ures. }\end{array}$ & 0.018 & 0.295 & 0.087 \\
\hline - & Multiple Correlation Coefficients & & 0.470 & \\
\hline - & Coefficient of Determination & & 0.221 & \\
\hline - & The Value of Calculated F & & 12.925 & \\
\hline - & Degree of Freedom & & 6,273 & \\
\hline - & The Value of Indexed F & & 2.802 & \\
\hline - & Level of Significant & & 0.000 & \\
\hline
\end{tabular}

In light of the above-mentioned facts, it was decided to reject the null hypothesis which states that there is no impact of cognitive CQ as one of the aspects of CQ on EJP. The alternative hypothesis has been accepted because the model of MRA has shown that there was fundamental relationship at a statistical significance level of 0.01 (according to F-test) between cognitive CQ as an independent variable and EJP as a dependent variable at a statistical significance level of 0.01 . According to T-test (See table 10).

\subsubsection{The Relationship between CQ (Meta-Cognitive CQ) and EJP}

Results shown in Table 11 reveal the following:

1) There is a statistically significant relationship between meta-cognitive CQ and EJP. It represents $42 \%$, according to the multiple correlation coefficients.

2) Meta-Cognitive CQ may interpret about $17 \%$ according to coefficient of determination (R-Square) of the total differentiation in the EJP.

3) The results of MRA reveal that the variables of the meta-cognitive CQ that better interpret differences in the EJP, for example, include the facts that " I adjust my cultural knowledge as I interact with people from a culture that is unfamiliar to me" (0.24), "I am conscious of the cultural knowledge I apply to cross-cultural interactions" (0.14), "I am conscious of the cultural knowledge I use when interacting with 
people with different cultural backgrounds" (0.11), and "I check the accuracy of my cultural knowledge as I interact with people from different cultures" $(0.02)$ as shown in table 11.

Table 11. The relationship between meta-cognitive CQ and EJP

\begin{tabular}{|c|c|c|c|c|}
\hline \multicolumn{2}{|r|}{ The Variables of Meta-Cognitive CQ } & \multirow{2}{*}{$\begin{array}{c}\text { Beta } \\
0.236^{* *}\end{array}$} & \multirow{2}{*}{$\begin{array}{c}\mathbf{R} \\
0.384\end{array}$} & \multirow{2}{*}{$\begin{array}{c}\mathbf{R}^{2} \\
0.147\end{array}$} \\
\hline & $\begin{array}{l}\text { I adjust my cultural knowledge as I interact with people from a } \\
\text { culture that is unfamiliar to me. }\end{array}$ & & & \\
\hline 2. & $\begin{array}{l}\text { I am conscious of the cultural knowledge I apply to cross-cultural } \\
\text { interactions. }\end{array}$ & 0.135 & 0.319 & 0.102 \\
\hline & $\begin{array}{l}\text { I am conscious of the cultural knowledge I use when interacting } \\
\text { with people with different cultural backgrounds. }\end{array}$ & 0.108 & 0.333 & 0.111 \\
\hline & $\begin{array}{l}\text { I check the accuracy of my cultural knowledge as I interact with } \\
\text { people from different cultures. }\end{array}$ & 0.013 & 0.293 & 0.086 \\
\hline - & Multiple Correlation Coefficients & & 0.416 & \\
\hline - & Coefficient of Determination & & 0.173 & \\
\hline - & The Value of Calculated F & & 14.425 & \\
\hline - & Degree of Freedom & & 4,275 & \\
\hline - & The Value of Indexed F & & 3,319 & \\
\hline - & Level of Significant & & 0.000 & \\
\hline
\end{tabular}

Accordingly, it was decided to reject the null hypothesis which states that there is no impact of meta-cognitive CQ as one of the aspects of CQ on EJP. The alternative hypothesis has been accepted because the model of MRA has shown that there was fundamental relationship at a statistical significance level of 0.01 (according to F-test) between meta-cognitive CQ as an independent variable and EJP as a dependent variable at a statistical significance level of 0.01 according to T-test (See table 12).

\subsubsection{The Relationship between CQ (Behavioral CQ) and EJP}

Results shown in Table (11) reveal the following:

1) There is a statistically significant relationship between behavioral CQ and EJP. It represents $46 \%$, according to the multiple correlation coefficients.

2) Behavioral CQ may interpret about $22 \%$ according to coefficient of determination (R-Square) of the total differentiation in the EJP.

3) The results of MRA reveal that the variables of the behavioral CQ that better interpret differences in the EJP, for example, include the facts that " I use pause and silence differently to suit different cross-cultural situations" (0.26), "I alter my facial expressions when a cross-cultural interaction requires it" (0.16), "I change my nonverbal behavior when a cross-cultural situation requires it" $(0.16)$, "I vary the rate of my speaking when a cross-cultural situation requires it" (0.08), and "I change my verbal behavior when a cross-cultural interaction requires it" $(0.08)$ as shown in table 12.

Table 12. The relationship between behavioral CQ and EJP

\begin{tabular}{|c|c|c|c|c|}
\hline & The Variables of Behavioral CQ & Beta & $\mathbf{R}$ & $\overline{\mathbf{R}^{2}}$ \\
\hline 1. & $\begin{array}{l}\text { I use pause and silence differently to suit different cross- } \\
\text { cultural situations. }\end{array}$ & $0.261^{* *}$ & 0.369 & 0.136 \\
\hline 2. & $\begin{array}{l}\text { I alter my facial expressions when a cross-cultural } \\
\text { interaction requires it. }\end{array}$ & $0.164^{*}$ & 0.328 & 0.107 \\
\hline 3. & $\begin{array}{l}\text { I change my nonverbal behavior when a cross-cultural } \\
\text { situation requires it. }\end{array}$ & $0.161^{*}$ & 0.352 & 0.124 \\
\hline
\end{tabular}




\begin{tabular}{|c|c|c|c|c|}
\hline 4. & $\begin{array}{l}\text { I vary the rate of my speaking when a cross-cultural } \\
\text { situation requires it. }\end{array}$ & 0.081 & 0.288 & 0.083 \\
\hline 5. & $\begin{array}{l}\text { I change my verbal behavior when a cross-cultural } \\
\text { interaction requires it. }\end{array}$ & 0.008 & 0.298 & 0.089 \\
\hline - & Multiple Correlation Coefficients & & 0.463 & \\
\hline - & Coefficient of Determination & & 0.214 & \\
\hline - & The Value of Calculated F & & 14.955 & \\
\hline - & Degree of Freedom & & 5,274 & \\
\hline - & The Value of Indexed F & & 3.017 & \\
\hline - & Level of Significant & & 0.000 & \\
\hline
\end{tabular}

As a result, it was decided to reject the null hypothesis which states that there is no impact of behavioral CQ as one of the aspects of CQ on EJP. The alternative hypothesis has been accepted because the model of MRA has shown that there was a fundamental relationship at a statistical significance level of 0.01 (according to F-test) between behavioral CQ as an independent variable and EJP as a dependent variable at a statistical significance level of 0.01 according to T-test (See table 12).

\section{Discussion of the Findings}

This study on the impact of CQ on EJP at King Abdel-Aziz hospital in Al-Taif Governorate has revealed a host of results which are worthy of study and interest. The most important findings are summed up as follows:

1) There are differences among the employees regarding their evaluative attitudes towards CQ. The aspects of CQ which better discriminate the employees include how employees are interested in knowing the legal and economic system of other cultures, and they are conscious of the cultural knowledge they use when interacting with people with different cultural backgrounds.

2) There are differences among employees regarding their evaluative attitudes towards EJP. The most important aspects of EJP which better discriminate employees are that the employees sometimes neglect aspects of the job they are obliged to perform.

3) There is a statistically significant relationship between the aspects of CQ (motivational CQ, cognitive CQ, meta-cognitive CQ, and behavioral CQ) and EJP at King Abdel-Aziz hospital in Al-Taif Governorate, KSA.

\section{Recommendations}

In the light of previous results, the most important recommendations include the following:

1) Managers should acknowledge the differences among the staff's culture. In other words, they should be culturally more open. In order to create a culturally intelligent organization, several aspects should be taken into consideration. Kaifi (2009b) explains, "In our rapidly changing world, there is a critical need for mutual understanding and communication among all people. There is a need for a new, more encompassing world view, as well as understanding and respecting all religions and cultures" (p. 1). Openness to experiences was found to facilitate intercultural group performance and to be related to all CQ dimensions.

2) Openness should be approached from two different angles. On the one hand, it is a personality trait, which can be relatively easily recognized and measured. Employees with this trait are probably more adaptable and better at accepting differences. On the other hand, openness can represent values learned and endorsed within a certain culture. Then identifying people who allocate the similar importance to these values may help in composing work groups. These values may be more or less endorsed or discouraged in organizations by the help of cultivating the according organizational culture.

3) Applying the aspects of CQ (meta-cognitive CQ, cognitive CQ, motivational CQ and behavioral CQ) will help to get through the surface and manifestation levels of diversity for tackling with the founding values-based diversity and identifying its potential advantages. 
4) Developing the CQ dimensions and skills will help to see beyond the surface level manifestations of diversity and thus understand the other better.

5) Those in charge of the hospital should pay attention to identifying and developing the CQ dimensions (meta-cognition, cognition, motivation, and behavior) of the employees.

6) A host of training programs to increase CQ which includes cultural awareness case studies, cross cultural behavior training through role playing, simulations. CQ should be embraced as part of the leadership development programs.

\section{Suggestions for Future Research}

The present study has attempted to disclose the impact of CQ on EJP at King Abdel-Aziz hospital in Al-Taif Governorate, but the scope of the study indicates the existence of other fields of other prospective studies of no less importance in this field, including:

1) It would be beneficial to compare the results of the findings of this study with other cases in different sectors in KSA. This comparison will provide the opportunity to generalize more results relate to a theory.

2) The relation between CQ and JEP could be further investigated in the industry sector to identify which parts of the performance are related to CQ.

3) CQ can be investigated in national companies, where the focus will be on the organizational CQ which is related to adapting to the culture of the organization. It would be interesting to examine whether this intelligence would affect JEP or not.

4) Researchers can measure the impacts of factors such as personality and self-efficacy on CQ.

5) The hypothesized effects of CQ should be studied empirically. Creating a test for estimating individual as well as organizational CQ, which would estimate employees' personality traits, values and other background characteristics, would enable it to move on from individual to group and organizational level in measuring and developing CQ.

\section{Conclusion and Implications}

The present paper aims at exploring the impact of CQ on EJP at King Abdel-Aziz hospital in Al-Taif Governorate, KSA. It is a contribution to the related literature as it provides results of an empirical explanatory case study.

The positive relationship between the CQ and EJP is confirmed and created by a perception of literature. It has turned out that CQ and its four aspects are related to EJP. Since people with high meta-cognitive CQ know how and when to use their culture, meta-cognitive CQ can have an impact on EJP. They apply multiple knowledge structures in terms of different conditions rather than relying upon their normal knowledge. Thus, they have a better understanding of expected functional behaviors in different cultural circumstances. Right and exact conception of job expectations in various cultural conditions is made easier thanks to cognitive CQ and it affects EJP.

Drawing on motivational theories, motivational CQ affects EJP motivational states of CQ. This increases individuals' resistance in doing their tasks better and affects CQ through more flexibility in verbal and nonverbal behaviors to meet others' expectations.

A major part of CQ skills and capabilities is acquirable regarding its relation with EJP. Thus, organizations and managers are obliged to inculcate and improve this type of intelligence in their employees and take necessary measures.

Employees should be initially investigated in terms of strengths and weaknesses of CQ in order to establish a starting point for next efforts. Then, they should pass trainings based on their weaknesses.

The present study contributes to CQ literature in several ways. First, it empirically supports the validity of the four dimensions of CQ in understanding how individuals adjust and perform their international assignment. Second, the relationships between CQ and EJP are investigated. This will help establish the best indicator to measure expatriate effectiveness. Future research should handle this in more detail. Third, this study fills the gap in expatriate management at King Abdel-Aziz hospital in Al-Taif Governorate, KSA. Findings of this study can be used to predict and understand expatriates' effectiveness in other hospitals.

Finally, according to results of the present study, CQ has important implications for practice, especially for selecting, training and developing a culturally intelligent workforce explaining why some people are more effective than others. Therefore, CQ should be taken into consideration and be further developed for training the 
employees at this hospital. The criteria for their evaluation should include CQ. Therefore, it will be reflected in the performance management system. This will positively affect the performance of these employees at King Abdel-Aziz hospital in Al-Taif Governorate, KSA.

\section{References}

Adidam, P., Gajre, S., \& Kejriwal, S. (2009). Cross-Cultural Competitive Intelligence Strategies. Market Intelligence and Planning, 27(5), 666-680. http://dx.doi.org/10.1108/02634500910977881

Alon, I., \& Higgins, J. (2005). Global Leadership Success through Emotional and Cultural Intelligences. Business Horizons, 48(6), 501-512. http://dx.doi.org/10.1016/j.bushor.2005.04.003

Amiri, A., Moghimi, S., \& Kazemi, M. (2010). Studying the Relationship between Cultural Intelligence and Employees' Performance. European Journal of Scientific Research, 42(3), 432-427.

Ang, S., Van Dyne, L., Koh, C., \& Ng, K. (2004). The Measurement of Cultural Intelligence. Paper Presented at the 2004 Academy of Management Meetings Symposium on Cultural Intelligence in the $21^{\text {st }}$ Century. New Orleans, LA.

Ang, S., Koh, C., \& Van Dyne, L. (2008). Development and Validation of the CQs: The Cultural Intelligence Scale. In S. Ang, \& L. Van Dyne(Eds.), Handbook on Cultural Intelligence: Theory, Management and Application. New York, M.E. Sharpe.

Ang, S., Livermore, D., \& Van Dyne, L. (2010). Cultural Intelligence: A Pathway for Leading in a Rapidly Globalizing World. In M. \&. Hannum(Eds.), Leading across Differences. San Francisco: Pfeiffer.

Ang, S., Van Dyne, L., \& Koh, C. (2006). Personality Correlates of the Four Factors Model of Cultural Intelligence. Group and Organization Management, 31, 100-123. http://dx.doi.org/10.1177/1059601105275267

Ang, S., Van Dyne, L., Koh, C., NG, K. Y., Templer, K., Tay, C., \& Chandrasekar, N. (2007). Cultural Intelligence: Its Measurement and Effects on Cultural Judgment and Decsion Making, Cultural Adaptation and Task Performance. Management and Organization Review, 3(3), 335-371. http://dx.doi.org/10.1111/j.1740-8784.2007.00082.x

Arora, P., \& Rohmetra, N. (2010). Cultural Intelligence: Leveraging Differences to Bridge the Gap in the International Hospitality Industry. International Review of Business Research Papers, 6(5), 216-234.

Ascalon, M. E., Schleicher, D. J., \& Born, M. P. (2008). Cross-Cultural Social Intelligence: An Assessment for Employees Working in Cross-National Contexts. Cross-Cultural Management, 15(2), 109-130. http://dx.doi.org/10.1108/13527600810870570

Babbie, E. (1998). The Practice of Social Research (6 ${ }^{\text {th }}$ Ed). Wadsworth Publishing Company, Belmont.

Berry, J., W., \& Ward, C. (2006). Commentary on Redefining Interactions across Cultures and Organizations. Group and Organization Management, 31(1), 64-77. http://dx.doi.org/10.1177/1059601105275264

Brislin, R., Worthley, R., \& McNab, B. (2006). Cultural Intelligence: Understanding Behaviors that Serve People's Goals. Group and Organization Management, 31, 40-45. http://dx.doi.org/10.1177/1059601105275262

Campbell, J. (1999). The Definition and Measurement of Performance in the New Age. In Ilgen, D., and E., Pulakos (Eds.), The Changing Nature of Performance: Implications for Staffing, Motivation and Development. San Francisco, Calif: Jossey-Bass: 399-429.

Creswell, J. (2008). Educational Research: Planning, Conducting and Evaluating Quantitative and Qualitative Research $\left(3^{\text {rd }}\right.$ Ed.). University of Nebraska, Pearson Educational International.

Dean, B. (2007). Cultural Intelligence in Global Leadership: A Model for Developing Culturally and Nationally Diverse Teams. A thesis Presented to Regent University School of Global Leadership \& Entrepreneurship, in Partial Fulfillment of the Requirements for the Degree of Doctor of Philosophy in Organizational Leadership.

Deng, L., \& Gibson, P. (2009). Mapping and Modeling the Capacities that Underlie Effective Cross-Cultural Leadership. Cross Cultural Management: An International Journal, 16(4), 247-366. http://dx.doi.org/10.1108/13527600911000339

Earley, P. C., \& Ang, S. (2003). Cultural Intelligence: Individual Interactions across Cultures. Stanford University Press, Palo, Alto. 
Earley, P. C. (2002). Redefining Interactions across Cultures and Organizations, Moving Forward with Cultural Intelligence. Research in Organizational Behavior, 24, 271-299. http://dx.doi.org/10.1016/S0191-3085(02)24008-3

Earley, C., \& Mosakowski, E. (2004). Cultural Intelligence. Harvard Business Review, 82(10), 139-146.

Edris, T. (2004). Marketing Research Methods of Measurement and Analysis and Testing of Hypotheses. University House, Alexandria.

Gabel, R., Dolan, S., \& Cerdin, J. (2005). Emotional Intelligences Predictor of Cultural Adjustment for Success in Global Assignments. Career Development International, 10(5), 375-395. http://dx.doi.org/10.1108/13620430510615300

Hofstede, G. (2001). Culture's Consequences: Comparing Values, Behaviors, Institutions, and Organizations across Nations. Thousand Oaks, CA: Sage.

Imai, L., \& Gelfand, M. (2007). Culturally Intelligent Negotiators: The Impact of CQ on Intercultural Negotiation Effectiveness. Academy of Management, Proceedings, 1-6.

Johnson, J., Lenartowicz, T., \& Apud, S. (2006). Cross-cultural Competence in International Business: Toward a Definition and a Model. Journal of International Business Studies, 37(4), 525-543. http://dx.doi.org/10.1057/palgrave.jibs.8400205

Kaifi, B. A. (2009a). $21^{\text {st }}$ Century Leadership in Healthcare. PP. 90-100. Chapter Twelve in the Pharmaceutical Technician Laboratory Manual by Sandeep Bansal. Jones and Bartlett Publications, Boston, Massachusetts.

Kaifi, B. A. (2009b). A Critical Hermeneutic Approach to Understanding Experiences of Selected Afghan-American Leaders Post-9/11 in the Bay Area. ProQuest Dissertation Service. University of San Francisco.

Katz, D., \& Kahn, R. (1978). The Social Psychology of Organizations (2 ${ }^{\text {nd }}$ Ed.). Wiley, New York: ISBN 0471023558 .

Kumar, N., \& Subramaniam, C. (2008). The Effects of Personality and Cultural Intelligence on International Assignment Effectiveness: A Review. Journal of Social Sciences, 4(4), 320-328. http://dx.doi.org/10.3844/jssp.2008.320.328

Law, K., Wong, C., \& Mobley, W. (1998). Toward a Taxonomy of Multidimensional Constructs. Academy of Management Review, 23, 741-755.

Lugo, M. (2007). An Examination of Cultural and Emotional Intelligences in the Development of Global Transformational Leadership Skills. A thesis Presented to Walden University School of Management, in Partial Fulfillment of the Requirements for the Degree of Doctor of Philosophy Applied Management and Decision Sciences.

Mayer, J., Caruso, R., \& Salovey, P. (2000). Emotional Intelligence Meets Traditional Standards for an Intelligence. Intelligence, 27(4), 267-298. http://dx.doi.org/10.1016/S0160-2896(99)00016-1

Moody, M. (2007). Adaptive Behavior in Intercultural Environments: The Relationship Between Cultural Intelligence Factors and BIG five Personality Traits. A Thesis Presented to George Washington University, in Partial Fulfillment of the Requirements for the Degree of Doctor of Philosophy.

Moon, T. (2010). Emotional Intelligence Correlates of the Four Factor Model of Cultural Intelligence. Journal of Managerial Psychology, 25(8), 876-898. http://dx.doi.org/10.1108/02683941011089134

Mujtaba, B. G., \& Kaifi, B. A. (2010). An Inquiry into Eastern Leadership Orientation of Working Adults in Afghanistan. Journal of Leadership Studies, 4(1), 36-46. http://dx.doi.org/10.1002/j1s.20153

Ng, K., \& Earley, P. (2006). Culture and Intelligence: Old Constructs, New Frontiers. Group and Organization Management, 31, 4-19. http://dx.doi.org/10.1177/1059601105275251

Ng, K., Dyne, L., \& Ang, S. (2009). From Experience to Experimental Learning: Cultural Intelligence as a Learning Capability for Global Leader Development. Academy of Mangement Learning and Education, 8(4), 511-526. http://dx.doi.org/10.5465/AMLE.2009.47785470

Ng, K., Van Dyne, L., \& Ang, S. (2009). Beyond International Experience: The Strategic Role of Cultural Intelligence for Executive Selection in IHRM. In P. Sparrow (Ed.), Handbook of International Human Resource Management. John Wiley \& Sons, PP. 97-113.

Ng, K., Van Dyne, L., \& Ang, S. (2009). Developing Global Leaders: The Role of International Experience \& 
Cultural Intelligence. In W. H. Mobley, Y. Wang, \& M. Li (Eds.), Advances in Global Leadership, 5, 225-250.

Peterson, B. (2004). Cultural Intelligence: A Guide to Working with People from other Cultures. Yarmouth, ME: Intercultural Press.

Rath, T., \& Conchie, B. (2009). Strengths Based-Leadership. New York: Gallup Press.

Schmidt, F., \& Hunter, J. (2000). Select on Intelligence. In E. A. Locke (Ed.), The Blackwell Handbook of Organizational Principles. Oxford: Blackwell, PP.3-14.

Sternberg R. (1986). Framework for Understanding Conceptions of Intelligence. In R. J. Sternberg R., \& D. K. Detterman (Eds.), What is Intelligence? Contemporary Viewpoints on its Nature and Definition. Norwood, New Jersey, Ablex, PP.3-15.

Sternberg, R., \& Detterman, D. (1986). What is intelligence? Contemporary Viewpoints on its Nature and Definition. Norwood, New Jersey, Ablex.

Sternberg, R., Forsythe, G., Hedlund, J., Horvath, J., Wagner, R., Williams, W., Snook, S., \& Grigorenko, E. (2000). Practical Intelligence in Everyday Life. New York, Cambridge University Press.

Stone-Romero, E., Stone, D. L., \& Salas, E. (2003). The Influence of Culture on Role Conceptions and Role Behavior in Organizations. Applied Psychology: An International Review, 52, 328-362. http://dx.doi.org/10.1111/1464-0597.00139

Thorndike, R., \& Stein, S. (1937). An Evaluation of the Attempts to Measure Social Intelligence. Psychological Bulletin, 34, 275-285. http://dx.doi.org/10.1037/h0053850

Triandis, H. C. (2006). Cultural Intelligence in Organizations. Group and Organization Management, 31, 20-26.

Van Dyne, L., \& Ang, S. (2008). The Sub-Dimensions of the Four Factor Model of Cultural Intelligence. Technical Report, Cultural Intelligence Center.

Van Dyne, L., Ang, S., \& Livermore, D. (2010). Cultural Intelligence: A Pathway for Leading in a Rapidly Globalizing World. In M. Hannum (Ed.), Leading across Differences. San Francisco: Pfeiffer, PP.131-138.

Williams, L., \& Anderson, S. (1991). Job Satisfaction and Organizational Commitment as Predictors of Organizational Citizenship and in-Role Behavior. Journal of Management, 17(3), 601-617. http://dx.doi.org/10.1177/014920639101700305 